Buana Sains Vol 17 No 2: 175-180, 2017

\title{
PEMANFATAN CAMPURAN PANGKASAN TUMBUHAN IN SITU DANKOTORAN TERNAK ULAT JERMAN UNTUK MENINGKATKAN PERTUMBUHAN DAN HASIL TANAMAN JAGUNG
}

\author{
Riyanto Djoko dan Presti Ameliawaty \\ Fakultas Pertanian Universitas Tribhuwana Tunggadewi Malang
}

\begin{abstract}
Field trial designed by a randomized block design factorial, three replication. The first factor is plant prunings 3 kinds of material mixed with cattle dung manure worms Germany and the second factor treatment fertilizer composition comprising a mixture of three kinds consists of: Tithoniadiversifolia, Cromolaenaodorata and Gliricidiasepium. Fertilizer composition comprising a mixture of: $90 \%$ of plants $+10 \%$ manure, $80 \%$ growth $+20 \%$ manure and $70 \%$ growth $+30 \%$ manure. Of the two factors obtained 9 treatment combinations. The observationdone for variable of : root dry weight, stem dry weight, dry weight of cob and dry seed weight per ear at harvest. Statistical analysis of the parameters of the observations were made using a variety of tests (test F) Random Block Factorial and continued with Duncan test level of 5\%.

Results of the experiments showed that: a). The use of a mixture of crop plants in situ with caterpillar droppings German influence on stem dry weight, root dry weight, dry weight and the weight of dry seed cob corn crop. b). The highest weight of dry seed treatment derived from the addition of a mixture of crop Gliricidia sp. $70 \%$ with caterpillar droppings Germany 30\% (165 grams), while the lowest of the crop mix treatment Titonia sp. 90\% with caterpillar droppings Germany 10\% (112.3 g).
\end{abstract}

Keywords: Crop plants, dirt caterpillar Germany, the increase in yield of corn

\section{PENDAHULUAN}

Dalam sistem pertanian dengan masukan rendah dan sustainable, masukan organik diharapkan terjadi secara "in situ", artinya bahan organik dihasilkan pada lahan yang sama dan bukan diambilkan dari tempat lain. Kualitas bahan organik sangat menentukan kecepatan proses dekomposisi dan mineralisasi bahan organik. Semakin baik kualitas bahan organik yang dimiliki maka akan semakin mempercepat proses dekomposisi dan mineralisasibahan organik tersebut. Usaha untuk meningkatkan kualitas bahan organik dapat dilakukan dengan menambah bahan organik lain yang berkualitas lebih tinggi (Handayanto et al., 1997). Pupuk kandang merupakan salah satu jenis bahan organik yang dikenal berkualitas tinggi (C/N: 14; C/P: 57). Tanaman jagung dimanfaatkan sebagai tanaman indicator penelitian karena tanaman jagung adalah salah satu jenis tanaman pangan penghasil karbohidrat yang terpenting di dunia selain gandum dan padi. Tujuan dari penelitian ini adalah: Penerapan dari pemanfaatan pangkasan tumbuhan in situ yang dicmpur dengan kotoran ternak ulat Jerman sebagai bahan pupuk untuk tanaman jagung yang bertujuan untuk mendapatkan kombinasi proporsi pangkasan tumbuhan in situ dan kotoran ternak ulatjerman yang memiliki potensi tinggi untuk meningkatkan pertumbuhan dan hasil tanaman jagung. 


\section{Metode Penelitian}

\section{Tempat dan Waktu}

Penelitian dilakukan di Desa Amadanom, Kecamatan Dampit, Kabupaten Malang. Percobaan di lapang menggunakan lahan milik petani dan untuk analisa tanah dan tanaman menggunakan Laboratarium milik Universitas Tribhuwana Tunggadewi dan Universitas Brawijaya Malang.

\section{Bahan dan Alat}

Alat dan bahan yang digunakan dalam penelitian adalah benih jagung, pupuk kandang kotoran ulat Jerman, EM-4, Sidamatrin, Conta Zola, dan alat tulis menulis. Jenis bahan pangkasan tumbuhan terdiri dari : Tithonia diversifolia, Cromolaena odorata dan Gliricidia sepium.

Alat-alat yang digunakan meliputi, alat-alat pengolah tanah dan menanam seperti cangkul, sabit, tugal; penggaris dan meteran untuk mengukur panjang, lebar daun dan tinggi tanaman pada percobaan lapangan.

\section{Desain Penelitian}

Penelitian dilakukan melalui percobaan lapangan yang disusun berdasarkan Rancangan Acak Kelompok Faktorial, diulang tiga kali. Faktor pertama merupakan perlakuan 3 macam bahan pangkasan tumbuhan dicampur dengan pupuk kandang kotoran ternak ulat Jerman dan faktor kedua perlakuan komposisi pupuk campuran terdiri dari 3 macam. Jenis bahan pangkasan tumbuhan terdiri dari : Tithonia diversifolia, Cromolaena odorata danGliricidia sepium. Komposisi pupuk campuran terdiri dari : $90 \%$ tumbuhan $+.10 \%$ kotoran, $80 \%$ tumbuhan $+20 \%$ kotoran dan $70 \%$ tumbuhan $+30 \%$ kotoran. Dari ke dua faktor diperoleh 9 kombinasi perlakuan dan ditambah 1 perlakuan sebagai kontrol. Kombinasi perlakuan disajikan pada Tabel 1 .

Tabel 1. Kombinasiperlakuanpenelitian

\begin{tabular}{|l|l|l|}
\hline No & Perlakuan & \multicolumn{1}{c|}{ Keterangan } \\
\hline 1 & Tit 10 & BiomasaTithoniadiversifolia $90 \%+$ kotoran ulat Jerman10 $\%$ \\
\hline 2 & Tit 20 & BiomasaTithoniadiversifolia $80 \%+$ kotoran ulat Jerman20 $\%$ \\
\hline 3 & Tit 30 & BiomasaTithoniadiversifolia $70 \%+$ kotoran ulat Jerman30 $\%$ \\
\hline 4 & Crom10 & Biomassa Cromolaena odorata $90 \%+$ kotoran ulat Jerman10 $\%$ \\
\hline 5 & Crom 20 & Biomassa Cromolaena odorata $80 \%+$ kotoran ulat Jerman20 $\%$ \\
\hline 6 & Crom30 & Biomassa Cromolaena odorata $70 \%+$ kotoran ulat Jerman30\% \\
\hline 7 & Gli10 & Biomasa Gliricidia sepium $90 \%+$ kotoran ulat Jerman10 $\%$ \\
\hline 8 & Gli20 & Biomasa Gliricidia sepium $80 \%+$ kotoran ulat Jerman20 \% \\
\hline 9 & Gli30 & Biomasa Gliricidia sepium $70 \%+$ kotoran ulat Jerman30 $\%$ \\
\hline 10 & Kontrol & Tanpa tambahan pupuk campuran \\
\hline
\end{tabular}

\section{Pelaksanaan Percobaan}

Pengolahan tanah untuk percobaan di lapangan ini dilakukan dengan mencangkul sekali, kemudian petak percobaan dicetak berukuran 3 X 2,5 m. Jarak antar petak dibuat parit selebar 40 $\mathrm{cm}$ dengan kedalaman $20 \mathrm{~cm}$. Bahan pangkasan tumbuhan liar dalam keadaan segar yang dimanfaatkan sebagai bahan percobaan dicacah dengan ukuran $2-4$ $\mathrm{cm}$, kemudian difermentasi bersamasama dengan pupuk kandang kotoran ternak ulat Jerman sesuai perlakuan. Setelah 2 minggu campuran bahan pangkasan tumbuhan dan pupuk kandang kotoran ternak ulat Jerman 
disebar pada petak percobaan sesuai dengan perlakuan dan ditutup dengan tanah dari galian antar petak sekaligus sebagai parit. Benih jagung yang ditanam ditugalkan sedalam $5 \mathrm{~cm}$ dengnan jarak tanam $20 \mathrm{~cm}$ dalam barisan dan $75 \mathrm{~cm}$ antar barisan. Setiap lubang ditanam 2 biji dan setelah tumbuh normal dijarangkan disisakan 1 batang. Pengaturan jarak tanam anjuran untuk mendapatkan populasi optimal dari jagung varietas " Arjuna " adalah 75 X 40 $\mathrm{cm}$ untuk 2 tanaman per lubang atau 75 $\mathrm{X} 20 \mathrm{~cm}$ untuk 1 tanaman perlubang sehingga diperoleh populasi tanaman 66.600 tanaman per ha (Sutoyo, 1999).

Usaha pengendalian hama dilakukan penyemprotan insektisida "Sidamathrin" dengan dosis $2 \mathrm{cc} / \mathrm{l}$ air paad saat tanaman mulai terserang hama. Untuk pengendalian penyakit tanaman disemprot dengan fungisida Conta Zola dengan dosis $2 \mathrm{cc} / 1$ air. Pendangiran dan pembubunan dilakukan sekali pada umur 4 minggu setelah tanam untuk mengurangi pertumbuhan gulma dan memperkokoh tegak tumbuhnya tanaman. Panen dilakukan ketika biji jagung sudah cukup masak, dengan warna biji kuning keemasan dan bila diitekan tidak mengeluarkan air serta apabila kulit jagung (klobot) sudah mulai mengering.

Parameter yang diamati pada percobaan lapangan ini meliputi : berat kering akar, berat kering batang, berat kering tongkol dan berat pipilan kering per tongkol pada saat panen.
Sebelum penelitian, dilakukan pengukuran terhadap kualitas campuran bahan pangkasan dan pupuk kandang sesuai dengan perlakuan meliputi : Corganik, N-total P-total dan K-total.

\section{Analisa Data \\ Analisa data terhadap parameter pengamatan dilakukan dengan menggunakan uji ragam (uji $F$ ) Rancangan Acak Kelompok Faktorial dan dilanjutkan dengan uji Duncan taraf $5 \%$.}

\section{Hasil dan Pembahasan}

a). Pengaruh Campuran Pangkasan Tumbuhan in situ dan Kotoran Ternak Ulat Jerman terhadap Berat Kering Batang Tanaman Jagung

Campuran pangkasan tumbuhan dan kotoran ternak ulat Jerman ternyata berpengaruh terhadap berat kering batang tanaman jagung seperti nampak pada Gambar 1. Berat kering tanaman jagung tertinggi diperoleh dari perlakuan campuran pangkasan tumbuhan Glirisidia $s p .70 \%$ dan kotoran ternak ulat Jerman $30 \%$ (101,7 gr). Sedang yang terendah dari perlakuan campuran pangkasan tumbuhan Titonia sp. $90 \%$ dan kotoran ternak ulat Jerman 10\% (66,7 gr). Hal ini sejalan dengan hasil pengamatan terhadap luas daun. Makin luas daun berdampak pada penambahan berat kering tanaman jagung. Dampak selanjutnya adalah penambahan hasil tanaman jagung.

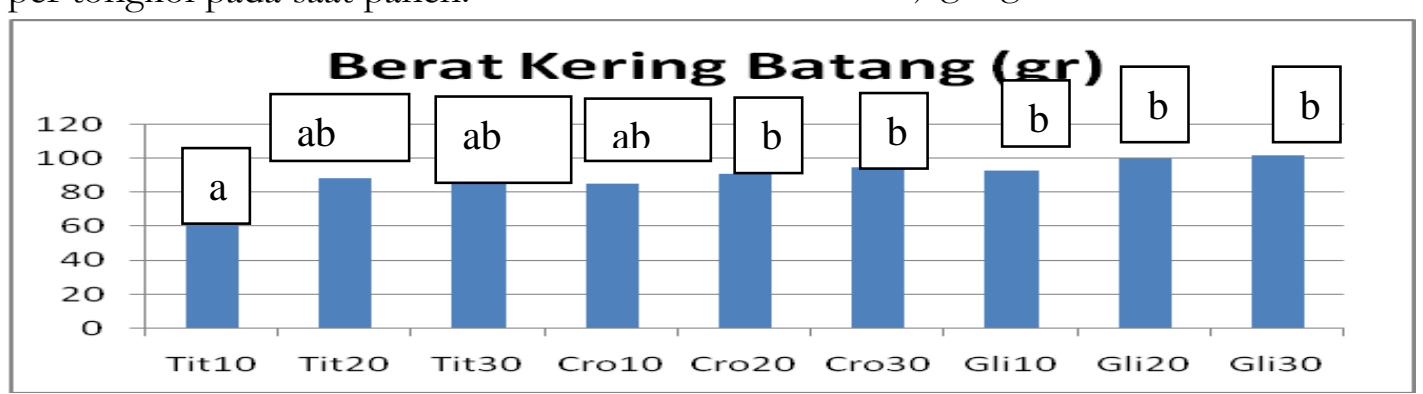

Gambar 1. Berat Kering Batang Tanaman Jagung 
b). Pengaruh Campuran Pangkasan Tumbuhan in situ dan Kotoran Ternak Ulat Jerman terhadap Berat Kering Akar Tanaman Jagung

Berat kering akar tanaman jagung dipengaruhi oleh perlakuan pemberian campuran pangkasan tumbuhan dan kotoran ternak ulat Jerman. Kenyataan ini nampak seperti pada Gamabar 2. Berat kering akar tertinggi diperoleh dari perlakuan penambahan campuran pangkasan Glirisidia sp. $70 \%$ dengan kotoran ulat Jerman 30\% (48,3 gr ), sedangkan yang terendah dari perlakuan campuran pangkasan Titonia sp. 90\% dan Cromolaena $5.90 \%$ dengan kotoran ulat Jerman 10\% (26,7 gr). Berat kering akar yang tinggi merupakan manifestasi dari pertumbuhan, perkembangan dan penyebaran akar yang baik. Keadaan ini diharapkan akan berdampak pada peningkatan penyerapan unsur hara, sehingga ada dampak selanjutnya yakni terjadinya peningkatan produksi baik secara kuantitas maupun kualitas.

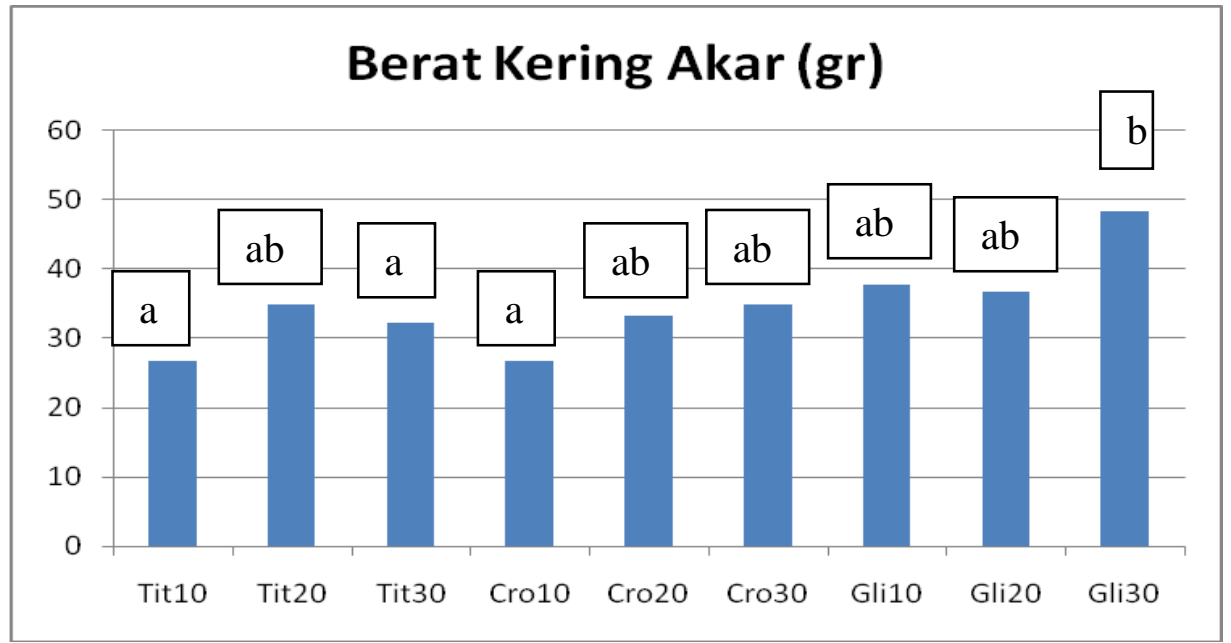

Gambar 2. Berat Kering Akar Tanaman Jagung

\section{c). Pengaruh Campuran Pangkasan Tumbuhan in situ dan Kotoran Ternak Ulat Jerman terhadap Berat Pipilan Kering Tanaman Jagung}

Analisa terhadap berat kering tongkol tanaman jagung didapatkan hasil bahwa berat kering tongkol tanaman jagung dipengaruhi oleh pemberian pupuk campuran antara pangkasan tumbuhan dan kotoran ulat Jerman seperti terlihat pada Gambar 3. Berat kering tongkol tertinggi diperoleh dari perlakuan penambahan campuran pangkasan Glirisidiasp. $70 \%$ dengan kotoran ulat
Jerman 30\% (208,3 gr ), sedangkan yang terendah dari perlakuan campuran pangkasan Titoniasp. 90\% dengan kotoran ulat Jerman 10\% (153,3 gr). Kenyataan ini menunjukkan bahwa pertumbuhan generatif tanaman jagung dipengaruhi oleh pertumbuhan vegatatifnya, terutama pertumbuhan luas daun, berat kering batang dan berat kering akar. Berat kering tongkol tanaman jagung sinkron dengan luas daun, berat kering batang dan berat kering akar dari tanaman jagung. 
R. Djoko dan P. Ameliawaty/Buana Sains Vol 17 No 2 : 175-180

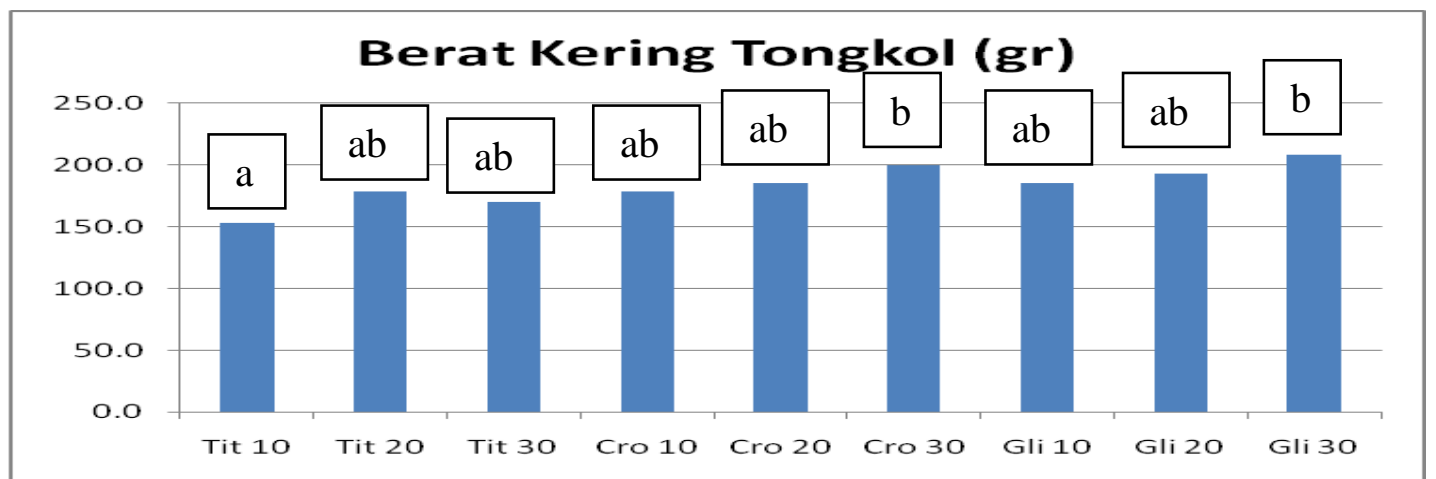

Gambar 3. Berat Kering Tongkol Tanaman Jagung

d). Pengaruh Campuran Pangkasan Tumbuhan in situ dan Kotoran Ternak Ulat Jerman terhadap Berat Pipilan Kering Tanaman Jagung

Berat pipilan kering tanaman jagung dipengaruhi oleh perlakuan penambahan campuran pangkasan tumbuhan dan kotoran ternak ulat Jerman. Berat pipilan kering tertinggi diperoleh dari perlakuan penambahan campuran pangkasan Glirisidia sp. $70 \%$ dengan kotoran ulat Jerman 30\% (165 gr ), sedangkan yang terendah dari perlakuan campuran pangkasan Titonia sp.90\% dengan kotoran ulat Jerman 10\% (112,3 gr). Kenyataan ini menunjukkan bahwa produksi pipilan tanaman jagung dipengaruhi oleh pertumbuhan vegetatif dari tanaman tersebut seperti yang berpengaruh terhadap berat kering tongkolnya. Apabila ingin mendapatkan produksi pipilan kering tanaman jagung yang optimal maka perlu diupayakan pertumbuhan vegetatif yang optimal pula.

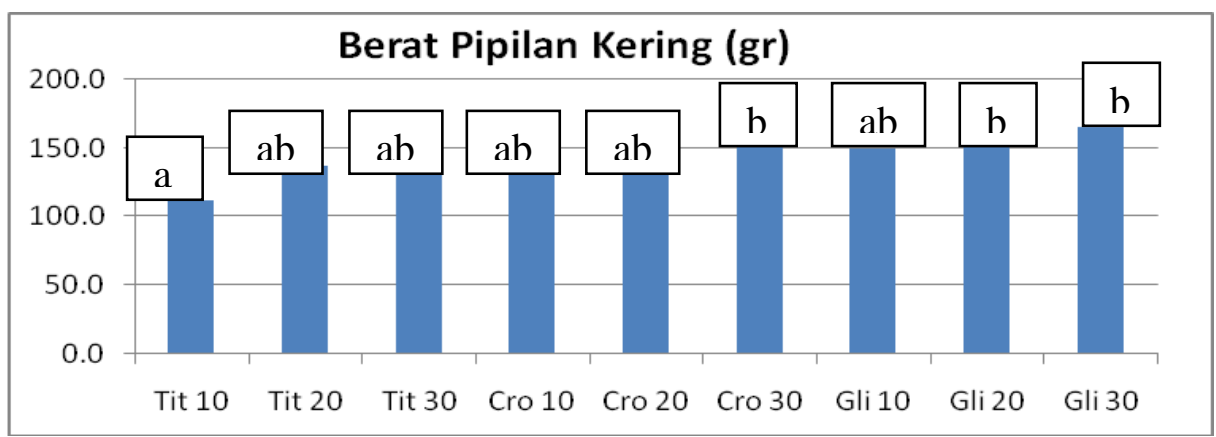

Gambar 4. Berat pipilan Kering Tanaman Jagung

\section{Kesimpulan}

1. Penggunaan campuran bahan pangkasan tumbuhan in situ dengan kotoran ulat Jerman berpengaruh terhadap pertambahan tinggi tanaman, luas daun, berat kering batang, berat kering akar, berat kering tongkol dan berat pipilan kering tanaman jagung.
2. Berat pipilan kering tertinggi diperoleh dari perlakuan penambahan campuran pangkasan Glirisidia sp. $70 \%$ dengan kotoran ulat Jerman 30\% (165 gr ), sedangkan yang terendah dari perlakuan campuran pangkasan Titonia sp. $90 \%$ dengan kotoran ulat Jerman $10 \%(112,3 \mathrm{gr})$. 
R. Djoko dan P. Ameliawaty/Buana Sains Vol 17 No 2 : 175-180

\section{Daftar Pustaka}

Anonim. 2015. KebutuhanUnsur Hara padaTanaman.http://www.tipsber kebun.com/kebutuhan-unsur-harapada-tanaman.html

Handayanto, E. 1997. Pengelolaan Kesuburan Tanah Secara Biologi Untuk Menuju Sistem Pertanian Sustainabel. Habitat. 102. 1 - 9.
Risnandar,

C.

2015.

JenisdanKarakteristikPupukKanda ng.http://alamtani.com/pupukkandang.html 2012-2015. Buletinagribisnis - alamtani.com Sutoyo. 1999. Respon Jagung Hibrida Prolifik dan Non Prolifik pada Pemupukan Nitrogen dan Populasi Tanaman. Tesis. Program PascaSarjanaUniversitasBrawijaya. Malang. 